\title{
Diffusing innovative road safety practice: A social network approach to identifying opinion leading U.S. cities
}

\author{
Seth LaJeunesse $^{a}$ (D), Stephen Heiny ${ }^{a}$, Kelly R. Evenson ${ }^{b}$ (D), Lisa M. Fiedler ${ }^{c}$, and Jill F. Cooper ${ }^{d}$ \\ ${ }^{a}$ University of North Carolina at Chapel Hill, Highway Safety Research Center, Chapel Hill, North Carolina; ${ }^{b}$ University of North Carolina at \\ Chapel Hill, Gillings School of Global Public Health, Department of Epidemiology, Chapel Hill, North Carolina; 'What Works Cities, Bloomberg \\ Philanthropies, New York, New York; 'University of California, Berkeley, Safe Transportation Research and Education Center, \\ Berkeley, California
}

\begin{abstract}
Objective: This study sought to identify opinion-leading U.S. cities in the realm of safe transportation systems by surveying road safety professionals and asking them to identify places that served as models for road safety.

Methods: Using a purposive sampling methodology, we surveyed professionals employed in road safety-related professions (e.g., transportation engineering, planning, public health, law enforcement, and emergency response). Using 183 professionals' complete responses, we carried out social network analysis to both describe the structure of intermunicipal advice-seeking patterns among road safety professionals and identify those municipalities with relatively high degrees of influence.

Results: We discovered a large intermunicipal monitoring network related to improving road user safety. Half of the network ties (50.4\%) crossed regional U.S. census boundaries. Social network statistics informed the identification of 7 opinion-leader and 4 boundary-spanning municipalities.

Conclusions: This study indicated a large intermunicipal monitoring network, half of which crossed regional boundaries. Road safety professionals have formed a country-spanning examplefollowing network on the topic of improving road user safety in the United States. Researchers and intervention teams can tap into this network to accelerate the uptake and spread of evidence-based road safety practices.
\end{abstract}

ARTICLE HISTORY

Received 30 April 2018

Accepted 17 September 2018

\section{KEYWORDS}

Safe systems; Vision Zero; social network analysis; diffusion of innovations; opinion leaders

\section{Introduction}

In the United States, the rapid diffusion of effective road safety practices is timely and critical. In 2016 , a total of 37,461 people died in motor vehicle crashes on roadways in the United States (Insurance Institute for Highway Safety, Highway Loss Data Institute 2017). This 2016 fatality figure represented a $5.6 \%$ increase from the previous year, the highest absolute number of roadway fatalities since 2007 , and highest fatality rate-estimated by accounting for the total number of vehicle miles traveled on U.S. roadways-since 2008.

The conviction that no one should be killed or seriously injured using the road network and that traffic deaths and injuries are preventable originated in the late 1990s in Sweden and The Netherlands as part of their innovative road safety strategies, Vision Zero and Sustainable Safety, respectively (International Transport Forum 2016). A few years later, in 2000, the State of Washington instituted a "Target Zero" initiative, which established a goal of achieving zero traffic deaths and injuries within 30 years (Thomas et al. 2015). Following this, in 2004, the state of Minnesota adopted its "Toward Zero Deaths" initiative (Clarke 2008). As of early 2018, about three dozen U.S. cities have adopted "Vision Zero" initiatives. In the U.S. context, adoption signifies government official commitment to devote additional resources to traffic safety, a vision for ending roadway fatalities and serious injuries, and the engagement of key professional groups, most often including those working in traffic engineering, law enforcement, and public health (Vision Zero Network 2018). Such programs are designed to accommodate human error, manage traffic speeds through self-explanatory road designs, and provide safety-related feedback to road users by ensuring alertness and rewarding compliance with safety laws and regulations (McAndrews 2013). These mostly city-led campaigns seek to achieve zero fatal and severe roadway injuries within the next few decades using various evidence-based safety strategies known to reduce the chance and impact of fatal and severe traffic injuries (Fleisher et al. 2016). Though researchers have identified promising, largely isolated interventions (e.g., modern roundabouts, speed humps, pedestrian refuge islands, curb extensions, automated speed cameras; Kim et al. 2017), we are unaware of any research that has examined the broader professional milieu in which traffic safety strategies are conceptualized and put into practice.

Diffusion of innovations (DOI) theory describes the process through which a concept or procedure-that is, an 
innovation-diffuses through a social system over time (Rogers 2003). According to DOI, innovations that possess certain characteristics-for example, their relative advantage over the status quo, ease of application, trialability, and the observability of results of implementation-are more likely to be adopted by users in a social system (Rogers 2003). Drawing upon DOI, researchers and intervention specialists have illustrated the adoption of various innovations, including utilitarian bicycling (Nehme et al. 2016), pedestrian and bicycle plans (Aytur et al. 2013), alternative fuel and electric vehicles (Jansson et al. 2017; Naor et al. 2015), and the children's use of bicycle helmets (Farley et al. 1996). Many of these scholars have discovered that people are most likely to adopt innovations when they are compatible with commonly held values (Nehme et al. 2016) and promoted by neighbors (Farley et al. 1996; Jansson et al. 2017).

In addition to describing and explaining patterns of innovation adoption, diffusion scholars have proposed ways of "designing for diffusion" (Dearing and Kreuter 2010, S100; Dearing et al. 2013; Dunn et al. 2012) - a process that involves tailoring an evidence-based intervention to increase practitioners' awareness of the intervention, enhance their attitude toward it, experiment with adopting the intervention, and sustain its implementation in practice (Dearing et al. 2013). Toward designing evidence-based interventions to more readily diffuse through social networks, scholars call for clearer descriptions of relationships among actors of systems (Blanchet 2013). Social network analysis guides researchers in illustrating the structure of relationships among actors working in various professional fields, such as public health (Luke and Harris 2007). Insight into informal advice-seeking networks allows for intervention teams to locate both individuals and groups seeking advice and those serving as sources of advice. Examining networks can also help intervention teams identify nonexistent, yet potentially beneficial relationships that could strengthen efforts to design innovations for diffusion (Dearing et al. 2017). By tapping into established relationships among professionalsmany of whom work in similar sectors, possess common backgrounds, and experience similar challenges-intervention teams can accelerate the spread of an innovation through a network (Rogers and Bhowmik 1970). In addition, researchers and intervention teams can visualize the adviceseeking network to estimate where in a network an intervention can best be seeded and tested (Dearing et al. 2017).

Prior work on DOI and implementation science suggests that to increase the likelihood of an organization's adoption of an innovation-for example, effective traffic safety practices-intervention teams should identify, engage, and highlight well-connected and influential actors and organizations (Dearing et al. 2013). Indeed, scholars have observed that opinion leaders can accelerate the spread of knowledge through social networks (Flodgren et al. 2011), and marketing professionals have recruited people with a high degree of social connections to diffuse targeted messaging through networks to good effect (Holliday et al. 2016).

In this study, we sought to identify influence among U.S. professional groups whose work addresses traffic safety issues. We believed that illustrating interconnections among actors in road safety across the United States could help accelerate the implementation of effective road safety practices nationwide. Our study-specific aims were 2-fold: (1) Describe the structure of informal intermunicipal example monitoring relationships among road safety professionals across the United States. (2) Identify which U.S. municipalities were most influential in terms of either opinion leadership or their capacity to broker relationships among professionals in different municipalities.

\section{Methods}

Social network metrics allow for the analysis of nodes (i.e., single actors, such as a person, an organization, or a municipality), descriptions of ways in which nodes are tied together, and analysis of entire networks themselves (Dearing et al. 2017). In this research effort, we conceptualized an intermunicipal network as one that referred to relationships between actors across U.S. municipal borders. Based upon conversations with professionals working in cities early to adopt Vision Zero initiatives, our research team hypothesized that road safety professionals would naturally look to the road safety-related activity of other municipalities when considering adopting a road safety-related innovation, such as a Vision Zero campaign. This study was approved by University of North Carolina at Chapel Hill Institutional Review Board and informed consent was obtained from each respondent prior to participation in the study.

\section{Survey participants}

The study population consisted of 1,738 road safety professionals representing 664 unique U.S. municipalities and working in transportation engineering, planning, public health-especially injury prevention-emergency response, and law enforcement. These professional groups often comprise the core of municipalities' Vision Zero task forces (Vision Zero Network 2018). We gathered individuals' professional emails from 2 membership directories (i.e., the American Public Health Association and Association of Pedestrian and Bicycle Professionals membership directories) and 2 conference attendee lists (i.e., the 2017 Lifesavers Conference and Transportation Research Board's annual meeting).

\section{Survey design and procedure}

Next, we developed an English-language survey instrument using Qualtrics surveying software (Qualtrics, Provo, UT), which we administered online over a 3-week period in June and July 2017. Prior to sharing the survey, we entered the professional emails of 1,738 road safety practitioners into the Qualtrics survey, thereby affording us the ability to calculate a precise response rate to and efficiently administer the survey. To pilot test the survey instrument, we recruited 2 road safety professionals - a transportation planner and a public health professional-to complete the survey and participate in cognitive debriefing toward enhancing the 
survey's content validity (Brod et al 2009). We refined survey response options and the wording of a few questions based upon their feedback. The final survey is available elsewhere (see appendix in Evenson et al. 2018).

We designed the survey to take $5 \mathrm{~min}$ to complete and included 2 screening questions to avoid engaging people uninterested in participating in the survey-that is, "Will you be participating in our survey?"- and to ensure that only targeted professional groups responded to the survey, we asked "Does your work involve understanding or improving the safety of people on roadways?" We programmed the survey software to send up to 3 reminders to complete the survey to each study invitee. The survey included questions about participants' professional titles and fields of work, their employment history, and example monitoring behavior at the interpersonal, interorganizational, and intermunicipal levels as it relates to other entities' outside of participants' workplaces "work on reducing roadway injuries and fatalities." In a review of techniques used to identify opinion leaders, Valente and Pumpuang (2007) discovered that researchers commonly employed sociometric methods, including asking participants to nominate sources of advice, to identify opinion leaders. Thus, we applied standard sociometric methods in this study (e.g., Dearing et al. 2017).

To assess intermunicipal example monitoring, we asked respondents to "list up to three municipalities whose example or reputation they follow with respect to their work on reducing roadway fatalities and injuries." Respondents were instructed that these municipalities could include urban, suburban, and rural municipalities in the United States and to provide the city and state for each listed municipality. We defined municipalities as our unit of analysis, because Vision Zero programs in the United States are most often led by a multidisciplinary task force or committee composed of high-ranking public officials (e.g., mayors) and professional groups (e.g., police, transportation planning and engineering, fire, emergency services, public works; Vision Zero Network 2018). Thus, survey respondents often worked in the same municipality as other respondents, producing a "many-to-many" network structure, as opposed to a "one-to-one" (e.g., email) or "one-to-many" (e.g., television broadcast) type of communicative structure (Jensen and Helles 2011).

We collected employment data by asking participants to indicate the fields in which they worked (i.e., planning; law enforcement; engineering; emergency management, such as emergency medical services [EMS]; public health, such as injury prevention; or some "other" field); length of tenure in the field in 5-year increments; their job title; their primary organizational affiliation; and the city and state in which their organization was located.

\section{Social network development}

To be included in the network analysis, participants must have provided their job title, organizational affiliation, and the nomination of at least one municipality outside of the respondent's own municipality as a source of advice. We then created an adjacency matrix for the intermunicipal networks in each of the major U.S. census regions (i.e., Northeast, South, Midwest, West), in which 1 indicated that a social modeling relationship existed between 2 municipalities and 0 indicated the absence of a relationship. The matrix was constructed such that the ego in the dyad was the advice seeker (i.e., the respondent's municipality) and the alter was the advice source or model (i.e., the municipality that the respondent identified as a model of transportation safety). We then used the adjacency matrix for the network analysis at the whole-network level using Gephi (Ver. 0.9.2 Gephi Consortium 2017), an open-source social network analysis and visualization software package. Descriptive statistics were performed at whole-network and nodal (i.e., municipal) levels using Stata (Ver. 15; Stata, College Station, TX).

\section{Network-level measures}

At the whole-network level, we calculated the number of nodes-in this case, nodes are unique municipalities referenced in the sample. There were 230 unique municipalities referenced either as a model or as a monitor of road safetyrelated practice. Ties-also termed edges or links-are interactions that connect nodes (i.e., municipalities in the network). We also calculated network density-the number of connections a node has divided by the total possible connections a node could have if all nodes were connected to all other nodes in the network-and the level of in-degree centrality by U.S. census region. In-degree centrality is a commonly used measure of opinion leadership (Rice and Yoshioka-Maxwell 2015), which involved counting the number of incoming ties that a node received.

\section{Nodal-level measures}

At the nodal level, because of our interest in accelerating diffusion of effective Vision Zero practices and organizational structures, we aimed to identify municipalities that emerged as opinion leaders. Opinion leaders were identified based upon municipalities' in-degree centrality-a count of the number of times a node was nominated by other nodes in the network. Adapting procedures from Dearing and colleagues (2017), we operationalized opinion-leading municipalities as having in-degrees of at least 2 standard deviations above the mean in-degree score of all nodes in the network.

In addition to identifying opinion leading municipalities, we discerned boundary-spanning municipalities, which were municipalities that connected 2 or more groups in the larger network. Attitudes and behaviors tend to be similar among homogenous groups (e.g., large, politically progressive U.S. cities) and boundary spanners tend to be more attuned to divergent ways of thinking and behaving. Bridge-building across gaps between groups can offer insight into approaches otherwise not considered (Burt 2004). Boundary spanners can therefore contribute to the generation of innovate ideas, which can lead to higher quality of work (Long et al. 2013). We identified boundary spanners in the intermunicipal network using the betweenness centrality score of each node. Betweenness centrality refers to the degree to which a node lies on the shortest path connecting 
other nodes in the network. In line with how we identified opinion leaders, we discerned boundary spanners as possessing a betweenness centrality threshold of at least 2 standard deviations above the mean betweenness centrality score of all nodes in the network.

\section{Results}

From the 1,738 individual contacts, 384 professionals indicated a willingness to participate in the survey, indicating in an initial response rate of $22 \%$. Including only those individuals whose work involved "understanding or improving the safety of people on roadways" $(n=334)$ and excluding participants who did not provide one or more of the following (i.e., their job title, organizational affiliation, and the nomination of at least one municipality outside of their own municipality whose example they monitor; $n=151$ ), we collected a total of 183 complete responses. This translated to an overall response rate of $10.5 \%(183 / 1,738)$ and a completion rate of $54.8 \%$ (183/ 334). Respondents worked in 111 unique U.S. municipalities.

Among all 183 respondents, nearly half identified as female and most worked in planning and engineering fields (64\%), with smaller proportions working in public health $(17 \%)$, law enforcement and emergency response (10\%), and "other" fields (e.g., community organizing, advocacy, academia; 9\%). A high proportion of respondents worked in their professional field for less than 10 years (37\%), with the next largest group working in their professional fields for 15 to 25 years $(26 \%)$. Further, more professionals worked in the South (41\%) and West (36\%) than in the Northeast $(10 \%)$ or Midwest (13\%) census regions (Table 1).

Response rates differed according to respondents' professional fields: $12.2 \%$ (117/957) planning/engineering; $6.8 \%$ (18/265) law enforcement/EMS; and 6.2\% (32/516) public health. Response rates were similar by census region: $7.2 \%$ (19/265) Northeast; 12\% (75/624) South; 7.1\% (23/323) Midwest; and $12.5 \%(66 / 526)$ West. Response rates are slightly higher than what is calculated because we lacked information on which emails went unread.

Respondents nominated an average of 2 municipalities (SD $=1.29$ ) whose example or reputation they follow as it relates to their work in road safety. Further, 119 or $51.7 \%$ of the municipalities nominated by survey respondents harbored no respondents in the initial sampling frame. The intermunicipal monitoring network was composed of 230 municipalities, ranging from 23 in the Northeast to 98 in the South. The network possessed 372 ties, half of which (50.4\%) crossed regional boundaries. Intermunicipal network density across all regions was low (0.03), indicating a small number of observed ties in proportion to the number of possible ties that could exist if all nodes were connected to all other nodes. The highest densities were among municipalities in the Northeast region (0.06) and the lowest densities among those in the South (0.01; Table 2).

We identified 7 opinion leaders in the intermunicipal monitoring network, with the count in regions ranging from 1 each in both the South and Midwest, 2 in the Northeast, and 3 in the West.
Table 1. Descriptive statistics for survey participants by U.S. census region $(n=183){ }^{\mathrm{a}}$

\begin{tabular}{lcccrc}
\hline & Northeast & South & Midwest & West & Total, N (\%) \\
\hline $\begin{array}{l}\text { Overall } \\
\text { Gender }\end{array}$ & $19(10)$ & $75(41)$ & $23(13)$ & $66(36)$ & 183 \\
$\quad$ Female & $9(47)$ & $40(53)$ & $12(52)$ & $28(42)$ & $89(49)$ \\
$\quad$ Male & $10(53)$ & $35(47)$ & $11(48)$ & $38(58)$ & $94(51)$ \\
$\begin{array}{l}\text { Professional field } \\
\quad \text { Planning/engineering }\end{array}$ & $11(58)$ & $38(51)$ & $15(65)$ & $53(80)$ & $117(64)$ \\
$\quad$ Law enforcement/EMS & $1(5)$ & $12(16)$ & $1(4)$ & $4(6)$ & $18(10)$ \\
$\quad$ Public health & $4(21)$ & $16(21)$ & $4(17)$ & $8(12)$ & $32(17)$ \\
$\quad$ Other field & $3(16)$ & $9(12)$ & $3(13)$ & $1(2)$ & $16(9)$ \\
Years worked in field & $7(37)$ & $24(32)$ & $8(35)$ & $29(44)$ & $68(37)$ \\
$\quad$ Less than 10 years & $5(26)$ & $17(23)$ & $4(17)$ & $9(14)$ & $35(19)$ \\
$\quad 10$ to 15 years & $3(16)$ & $19(25)$ & $5(22)$ & $20(30)$ & $47(26)$ \\
$\quad 15$ to 25 years & $4(21)$ & $15(20)$ & $6(26)$ & $8(12)$ & $33(18)$ \\
$\quad$ More than 25 years & & & & & \\
\hline
\end{tabular}

${ }^{a}$ Northeast includes participants from the following states: $C T, M A, M E, N J, N Y$ PA, and VT; South from AR, DC, FL, GA, KY, LA, MD, NC, SC, TN, TX, VA Midwest from IA, IL, IN, MI, MN, MO, NE, OH, and Wl; and West from $A Z$, $\mathrm{CA}, \mathrm{CO}, \mathrm{HI}, \mathrm{ID}, \mathrm{MT}, \mathrm{NM}, \mathrm{OR}$, and WA.

Across the network, the opinion-leading municipalities were, in order of in-degree centrality, New York, New York; Portland, Oregon; Seattle, Washington; San Francisco, California; Minneapolis, Minnesota; Washington, D.C.; and Boston, Massachusetts. We also identified 4 boundary-spanning municipalities, with 2 boundary spanners in the West, 1 in each of the Northeast and Midwest regions, and none in the South. Boundary-spanning municipalities included, in order of higher to lesser betweenness centrality, New York, New York; Portland, Oregon; Minneapolis, Minnesota; and Seattle, Washington. The Vision Zero Network (2018) has recognized all of these municipalities as maintaining Vision Zero programs.

\section{Discussion}

In this study, we aimed to identify sources of influence among professionals working in municipalities' road safety systems. Surveying professionals in planning and engineering, public health, law enforcement and emergency response, we discovered a large intermunicipal example monitoring network, with about half of the intermunicipal ties crossing regional census boundaries. We identified 7 opinion leaders in the intermunicipal network within all major census regions in the United States, with a concentration of opinion leader cities in the Northeast and West regions. Further, we identified 4 boundary-spanning municipalities, 2 of which were in the West. More than half of the municipalities nominated by survey respondents were not in the initial sampling frame, which is consistent with prior work focused on identifying opinion leaders. That is, those who serve as sources of advice are less likely to look to others for inspiration, especially from those who tend to seek advice (Agneessens and Wittek 2011; Škerlavaj et al. 2010). Our results suggest that road safety professionals have formed a country-spanning network of example monitoring on the topic of improving road user safety in the United States. Reciprocal example monitoring is relatively strong in the Northeast region of the United States and weaker in the South region, with a concentration of opinion-leading and boundaryspanning municipalities in the West census region.

Our objective was to describe the extent and structure of example-monitoring networks among a diverse sample of road 
Table 2. Measures for intercity example-monitoring network by U.S. census region

\begin{tabular}{|c|c|c|c|c|c|c|}
\hline & Northeast & South & Midwest & West & $\mathrm{M}(\mathrm{SD})$ & Total \\
\hline \multicolumn{7}{|l|}{ Network Level } \\
\hline $\mathrm{N}$ nodes & 23 & 98 & 44 & 65 & $57.5(32)$ & 230 \\
\hline $\mathrm{N}$ example sources & 5 & 39 & 24 & 29 & $24.3(14.3)$ & 97 \\
\hline $\mathrm{N}$ example seekers & 9 & 32 & 15 & 29 & $21.3(11)$ & 85 \\
\hline $\mathrm{N}$ ties & 62 & 104 & 52 & 158 & $94(48.3)$ & 375 \\
\hline $\mathrm{N}$ intercity ties & 26 & 84 & 26 & 53 & $47.3(27.6)$ & 189 \\
\hline Density & 0.06 & 0.01 & 0.01 & 0.02 & $0.03(0.02)$ & \\
\hline In-degree centralization & 5.4 & 4.9 & 2.3 & 2.1 & $3.7(1.7)$ & \\
\hline \multicolumn{7}{|l|}{ Nodal level } \\
\hline \multicolumn{7}{|l|}{ In-degree centrality } \\
\hline $\mathrm{N}$ opinion leaders ${ }^{\mathrm{a}}$ & 2 & 1 & 1 & 3 & $1.75(0.96)$ & 7 \\
\hline In-degree, all nodes, M (SD) & $5.4(16.5)$ & $2.1(3.8)$ & $2.3(4.4)$ & $4.9(10.4)$ & $3.7(1.7)$ & \\
\hline In-degree, opinion leaders, M (SD) & $49.5(40.3)$ & $22(-)$ & $24(-)$ & $26.3(21.8)$ & $30.5(12.8)$ & \\
\hline \multicolumn{7}{|l|}{ Betweenness centrality } \\
\hline $\mathrm{N}$ boundary spanners ${ }^{\mathrm{b}}$ & 1 & 0 & 1 & 2 & $1(0.82)$ & 4 \\
\hline Betweenness centrality, all nodes, M (SD) & $111.6(311.9)$ & $39(92.1)$ & $91.7(161.7)$ & $47.9(162.5)$ & $72.6(34.8)$ & \\
\hline Betweenness centrality, boundary spanners, M (SD) & $2,577.1(-)$ & - & $934.1(-)$ & $1,289.6(672.1)$ & $1,600.3(864.4)$ & \\
\hline
\end{tabular}

apinion leaders were defined as all nodes with in-degree centrality scores of at least 2 standard deviations above the mean.

${ }^{b}$ Boundary spanners were defined as all nodes with betweenness centrality scores of at least 2 standard deviations above the mean.

safety professionals working in the United States. In a related research endeavor (Evenson et al. 2018), we discovered that awareness of Vision Zero campaigns was high among road safety professionals, particularly among those working in planning and transportation engineering fields. Moreover, professionals in law enforcement, emergency response, and public health have become involved in Vision Zero programming in more recent years, suggesting that these types of campaigns are diffusing across traditional professional boundaries.

The example-monitoring network described in this study can guide intervention teams in facilitating exchange of best practices among seekers and sources of road safety advice. Because we identified opinion-leading municipalities using by their central position in a social network rather than through self-identification methods (e.g., Valente and Pumpuang 2007), opinion leaders may lack awareness of their role as models for road safety practice. Similarly, boundary spanners may be unaware of their structural position in the road safety network. Thus, researchers and intervention teams can work with these leaders and brokers and connect them with municipalities seeking to institute Vision Zero and similar road safety programs. For example, several respondents from Atlanta referenced Seattle and New York City as models of road safety programming, and several respondents from Seattle nominated New York City as a traffic safety model. Respondents in New York City nominated Seattle as a traffic safety model municipality but not Atlanta. Because Seattle-based professionals work within a boundary-spanning municipality, these professionals could broker practice-focused exchanges among themselves and professionals in Atlanta and New York City.

Additionally, researchers could work with municipal opinion leaders to seed evidence-based, yet uncommonly applied road safety countermeasures and procedures in model municipalities (e.g., restricting car access in the city center, conducting random driver breath testing, commissioning independent reviews of cities' safety programs, etc.; see Fleisher et al. [2016] for a review of U.S. cities' traffic safety practices) with the intention of inspiring advice-seeking municipalities to adopt these evidence-based safety strategies. Indeed, by leveraging identified relationships among road safety professionals across municipal lines, intervention teams can accelerate the spread of effective practices throughout the United States.

Though to our knowledge this is the first depiction of an intermunicipal network of informal professional example monitoring in the traffic safety field, our analysis possessed a few notable limitations. The response rate was low-though not lower than is commonly reported (e.g., Sinclair et al. 2012). Because we were unable to verify receipt of the email invitation, the response rate is likely higher than reported. Moreover, our survey response pattern was partial and varied according to respondents' professional fields. For example, planners and engineers were overrepresented in our sample, which may have biased our results to favor these groups' considerations of model U.S. municipalities for road safety. Additionally, the data collection relied on a cross-sectional survey. Longitudinal studies would lend insight into the trajectories that road safety professionals follow over time in choosing their collaborators, especially as the state of road safety practice evolves, as novel technologies are introduced, and as demographics shift among metropolitan areas of the United States. Social network data such as we have presented here show relationships among road safety professionals and municipalities as reported by the survey respondents. It is natural to detect nodes in the network with high amounts of in-degree centrality, but what is less evident are unreported relationships between municipalities. Thus, this analysis should be considered an underrepresentation of the actual example-monitoring network for improving road safety practices. At first professionals might decide to strengthen their involvement in a disciplinary field by increasing the number of collaborators in that field. Subsequently, they might decide to collaborate with others outside their own field and therefore establish ties with new disciplinary areas (Lambiotte and Panzarasa 2009). As such, further research is needed to identify more representative municipal network structures, as well as to explore the ever-changing nature of road safety programming within and among U.S. municipalities.

It appears that road safety professionals look to other municipalities, often ones not geographically close to them, as exemplars for improving road user safety. This intermunicipal example-monitoring network related to traffic safety is an opportunity to significantly improve road user safety 
across the United States. By facilitating exchange among municipalities seeking advice and those modeling best practices, as well as broadcasting municipalities' employment of evidence-based safety countermeasures, researchers and intervention teams can strategically and rapidly diffuse effective road safety programming.

\section{Funding}

This research has been funded by the Collaborative Sciences Center for Road Safety, a National University Transportation Center supporting the U.S. Department of Transportation's research priority of promoting safety.

\section{ORCID}

Seth LaJeunesse (D) http://orcid.org/0000-0003-4908-3823

Kelly R. Evenson (iD) http://orcid.org/0000-0002-3720-5830

\section{References}

Agneessens F, Wittek R. Where do intra-organizational advice relations come from? The role of informal status and social capital in social exchange. Soc Networks. 2011;34:333-345. doi: 10.1016/j.socnet.2011.04.002.

Aytur SA, Rodriguez DA, Kerr ZY, Ji K, Evenson KR. Spatial and temporal patterns of North Carolina pedestrian and bicycle plans. J Public Health Manag. 2013;19:S83-S88. doi: 10.1097/PHH.0b013e31828404a0.

Blanchet K. How to facilitate social contagion? Int J Health Policy Manag. 2013;1:189-192. doi: 10.15171/ijhpm.2013.35.

Brod M, Tesler LE, Christensen TL. Qualitative research and content validity: developing best practices based on science and experience. Qual Life Res. 2009;18:1263-1278. doi: 10.1007/s11136-009-9540-9.

Burt RS. Structural holes and good ideas. Amer J Sociol. 2004;110:349-399.

Clarke S. The quest for zero fatalities: a comprehensive program aims to eliminate deaths on Utah's roadways. Public Roads. 2008;72:2-7.

Dearing JW. Applying diffusion of innovation theory to intervention development. Res Soc Work Pract. 2009;19:503-518. doi:10.1177/ 1049731509335569.

Dearing JW, Beacom A, Chamberlain S, et al. Pathways for best practice diffusion: the structure of informal relationships in Canada's long-term care sector. Implement Sci. 2017;12. doi: 10.1186/s13012-017-0542-7.

Dearing JW, Kreuter MW. Designing for diffusion: How can we increase uptake of cancer communication innovations? Patient Educ Couns. 2010;81:S100-S110. doi: 10.1016/j.pec.2010.10.013.

Dearing JW, Smith DK, Larson RS, Estabrooks CA. Designing for diffusion of a biomedical intervention. Am J Prev Med. 2013;44: S70-S76. doi: 10.1016/j.amepre.2012.09.038.

Dunn AL, Buller DB, Dearing JW, et al. Adopting an evidence-based lifestyle physical activity program: dissemination study design and methods. Transl Behav Med. 2012;2(2):199-208. doi: 10.1007/s13142-011-0063-x.

Evenson KR, LaJeunesse S, Heiny S. Awareness of Vision Zero among United States' road safety professionals. Inj Epidemiol. 2018;5(21): 1-6. doi: 10.1186/s40621-018-0151-1.

Farley C, Haddad S, Brown B. The effects of a 4-year program promoting bicycle helmet use among children in Quebec. Am J Public Health. 1996;86:46-51. doi: 10.2105/AJPH.86.1.46.

Fleisher A, Wier M, Hunter M. A vision for transportation safety framework for identifying best practice strategies to advance Vision Zero. Transp Res Rec. 2016;2582:72-86.

Flodgren G, Parmelli E, Doumit G, et al. Local opinion leaders: Effects on professional practice and health care outcomes. Cochrane Database Syst Rev. 2011;(8):CD000125. doi: 10.1002/14651858.CD000125.

Gephi [computer program]. Ver. 0.9.2. Paris, France: Gephi Consortium; 2017.

Holliday J, Audrey S, Campbell R, Moore L. Identifying well-connected opinion leaders for informal health promotion: the example of the
ASSIST smoking prevention program. Health Commun. 2016;31: 946-953. doi: 10.1080/10410236.2015.1020264.

Insurance Institute for Highway Safety, Highway Loss Data Institute. General statistics: fatality facts. 2017. Available at: http://www.iihs. org/iihs/topics/t/general-statistics/fatalityfacts/overview-of-fatalityfacts. Accessed January 3, 2018.

International Transport Forum. Zero Road Deaths and Serious Injuries: Leading a Paradigm Shift to a Safe System. Paris, France: Organisation for Economic Co-operation and Development; 2016.

Jansson J, Pettersson T, Mannberg A, Brannlund R, Lindgren U. Adoption of alternative fuel vehicles: Influence from neighbors, family and coworkers. Transp Res D Transp Environ. 2017;54:61-73. doi: $10.1016 /$ j.trd.2017.04.012.

Jensen KB, Helles R. The Internet as a cultural forum: Implications for research. New Media Soc. 2011;13:517-533. doi: 10.1177/ 1461444810373531.

Kim E, Muennig P, Rosen Z. Vision Zero: a toolkit for road safety in the modern era. Inj Epidemiol. 2017;4:1-9. doi: 10.1186/s40621-0160098-z.

Lambiotte R, Panzarasa P. Communities, knowledge creation, and information diffusion. J Informetr. 2009;3(3):180-190. doi: 10.1016/ j.joi.2009.03.007.

Long JC, Cunningham FC, Braithwaite J. Bridges, brokers and boundary spanners in collaborative networks: a systematic review. $B M C$ Health Serv Res. 2013;13:158-170.

Luke DA, Harris JK. Network analysis in public health: history, methods, and applications. Annu Rev Public Health. 2007;28:69-93. doi: 10.1146/annurev.publhealth.28.021406.144132.

McAndrews C. Road safety as a shared responsibility and a public problem in Swedish road safety policy. Sci Technol Hum Val. 2013; 38:749-772. doi: 10.1177/0162243913493675.

Naor M, Bernardes ES, Druehl CT, Shiftan Y. Overcoming barriers to adoption of environmentally-friendly innovations through design and strategy: Learning from the failure of an electric vehicle infrastructure firm. Int J Operat Product Manage. 2015;35:26-59. doi: 10.1108/IJOPM-06-2012-0220.

Nehme E, Perez A, Ranjit N, Amick B, Kohl H. Behavioral theory and transportation cycling research: application of diffusion of innovations. J Transp Health. 2016;3:346-356. doi: 10.1016/j.jth. 2016.05.127.

Research Core Qualtrics (for Windows) [computer program]. 2017.

Rice E, Yoshioka-Maxwell A. Social network analysis as a toolkit for the science of social work. J Soc Soc Work Res. 2015;6:369-383. doi: $10.1086 / 682723$.

Rogers EM. Diffusion of Innovations. 5th ed. New York, NY: Free Press; 2003.

Rogers EM, Bhowmik DK. Homophily-heterophily: relational concepts for communication research. Public Opin Q. 1970;34:523-538. doi: $10.1086 / 267838$.

Sinclair M, O’Toole J, Malawaraarachchi M, Leder K. Comparison of response rates and cost-effectiveness for a community-based survey: postal, Internet and telephone modes with generic or personalised recruitment approaches. BMC Med Res Methodol. 2012;12:132-132. doi: 10.1186/1471-2288-12-132.

Škerlavaj M, Dimovski V, Desouza KC. Patterns and structures of intra-organizational learning networks within a knowledgeintensive organization. J Inf Technol. 2010;25:189-204. doi: 10.1057/ jit.2010.3.

STATA statistical software (for Windows) [computer program]. Ver. 15. College Station, TX: StataCorp; 2017.

Thomas FD, Blomberg RD, Masten SV, et al. Evaluation of the Washington State Target Zero Teams Project. 2015. Available at: https://www.nhtsa.gov/sites/nhtsa.dot.gov/files/812097-wa-statetargetzeroproject.pdf. Accessed January 3, 2018.

Valente TW, Pumpuang P. Identifying opinion leaders to promote behavior change. Health Educ Behav. 2007;34:881-896. doi: 10.1177/ 1090198106297855.

Vision Zero Network. Vision Zero cities map. 2018. Available at: https:/visionzeronetwork.org/resources/vision-zero-cities/. Accessed February 20, 2018. 